\title{
Performance of Non-CFC Refrigerants for Low-Temperature Refrigeration
}

\author{
Leelananda Rajapaksha
}

Abstract: As a result of the worldwide ban on chlorinated refrigerants two widely used low temperature refrigerants; R13 and R503, are being made unavailable to the refrigeration industry. As for the present, alternative refrigerants for these fluids are very limited. This paper assesses the suitability of some logically screened non-CFC refrigerants and azeotropic mixtures for low temperature cooling applications. The analysis is based on thermal-physical properties and simulated vapour compression refrigeration cycle performance of the fluids. The screening process identified two fluorocarbons (R116 and R14) and one hydrocarbon (R170) as potential non-CFC replacements. Further, the study reveals that the properties of fluorocarbon R116, mixtures R508A and R508B correlate well with those of R13 and R503. It is also found that R14 possesses desired property behaviour of a refrigerant for cooling application close to $-100^{\circ} \mathrm{C}$ or below, however reasonable vapour pressures, volumes and discharge tempcratures need to be obtained preferably by making a blend with a second fluid.

Keywords: Low-temperature refrigeration, mixtures, COP, efficiency, vapour compression systems

\section{Background}

Expanding knowledge on adverse environmental implications ofchlorinated refrigerantsintensified the global search for environmentally acceptable, chemically and thermally stable alternatives. However, current research on refrigerants reveal that the chances for the discovery of an ideal refrigerant that meets all the environmental and performance criterion are very unlikely $[1,2,3,4]$. Among different applications of refrigeration, one area that faces challenges and difficulties in finding suitable alternatives is low temperature applications; say those operating below $-50^{\circ} \mathrm{C}$. At such low temperatures, cascade or multistage refrigeration systems are usually employed; mostly in applications of food processing, pharmaceuticals and chemical processing [5].

In general, when selecting a refrigerant for a specified vapour compression application, a trade off situation exists between the cooling capacity and the efficiency [4]. The positions of the condensing and evaporating temperatures relative to the critical point temperature influence the mass and volume flow rates of a refrigerant. As a result, different refrigerants will have different system efficiencies when delivering a specified cooling duty. In addition, the slope of the saturated liquid line indicate the likely loss of refrigerating effect due to formation of flash gas during expansion from condensing to evaporating pressure. Further, limitations of the refrigerants themselves appear, such as considerable variation of properties, when working at very low temperatures [6].

Refrigerants R13 (CFC) and R503 (CFC/HCF), with normal boiling points -81.3 and $-87.5{ }^{\circ} \mathrm{C}$ respectively, possess most of the desired thermalphysical properties suitable for low-temperature applications. These two refrigerants have been very successful working fluids in lower cycles of cascade refrigeration systems. However both these refrigerants are being phased out. Presently hydorfluoro-carbons (HFC), fluorocarbons (FC), hydrocar-bons (IIC) [2] and carbon dioxide [7], are considered as replacements. However, the complexity of the molecules and thermalphysical properties of the alternative refrigerants decide their efficiency and suitability for the intended low temperature applications. This paper investigates the suitability and asses associated parameters of certain appropriately screened refrigerants, $\mathrm{FC}, \mathrm{HC}, \mathrm{HCFC}$ etc., for low temperature cooling applications below $-50^{\circ} \mathrm{C}$

Eng.(Prof.) Leelananda Rajapaksha, MIE(SLri Lanku), MIIAR, CC. Eng, MIMechE, BScEng. (tirst Class Hons), MEng: PhD, Assucinte Professor, Department of Mechanial Enguneerng, Fnculty of Engineering, Unizersity of Peradeniya. 


\section{Nomenclature}

\section{Notations}

COP Coefficient of performance

$\mathrm{C}_{\mathbf{v}} \quad$ Constant volume specific heat $(\mathrm{kJ} / \mathrm{kgK})$

dT Degree of superheat or subcool

LFL Lower flammability limit

P Pressure $(\mathrm{kPa})$

s $\quad$ Entropy $(\mathrm{kJ} / \mathrm{kgK})$

T Temperature $\left({ }^{\circ} \mathrm{C}\right)$

Tr Reduced temperature

V Volume (m3)

\begin{tabular}{ll}
\multicolumn{2}{l}{ Subscripts } \\
atm & Atmospheric \\
buble & Bubble point \\
cnd & Condensing, condenser \\
crt & Critical \\
evp & Evaporation, evaporator \\
NBP & Normal boiling point \\
sc & Subcool \\
sht & Superheat
\end{tabular}

\section{Formulation}

3.1 Property behaviours and their implications on refrigeration cycle performance

Boiling point and critical point temperatures, specific heat, latent heat of evaporation, specific volume of vapour, operating pressures at condensing and evaporating temperatures mainly form the thermal physical property creation in selecting a refrigerant for a specified application [4]. In addition, degree of environmental friendliness, flammability, chemical and thermal stability, compatibility with material and lubricants, odour, toxicity, broadly forms the basis for other important aspects of selection process [8]. The evaporator pressure is preferably maintained slightly above atmospheric to avoid inward leakages. A safe and moderate condensing pressure is preferred on safety grounds.

Further, as shown in Fig. 1, due to the inherent converging shape (towards critical point, though vapour domes not necessarily be symmetrical, as can be seen from actual shapes in Fig 5 ) of the vapour dome, operating too close to critical point has the disadvantage of relatively smaller condensing latent heat per unit mass of refrigerant circulated [3]. On one hand, this suggests need for a relatively larger single phase heat transfer area of the condenser. On the other hand, since only a smaller amount of heat is transported per unit mass flow of refrigerant, the coefficient of performance or the system efficiency is likely to be affected. On the contrary, operating further away from the critical point, the evaporation latent heat will be relatively larger and so will be the vapour volume, of which the former relates to a higher cooling effect per unit mass of refrigerant circulated and the latter corresponds to handling of larger refrigerant volumes. Therefore the refrigerant selection process needs to strike a balance between the cooling capacity and the efficiency of the cycle.

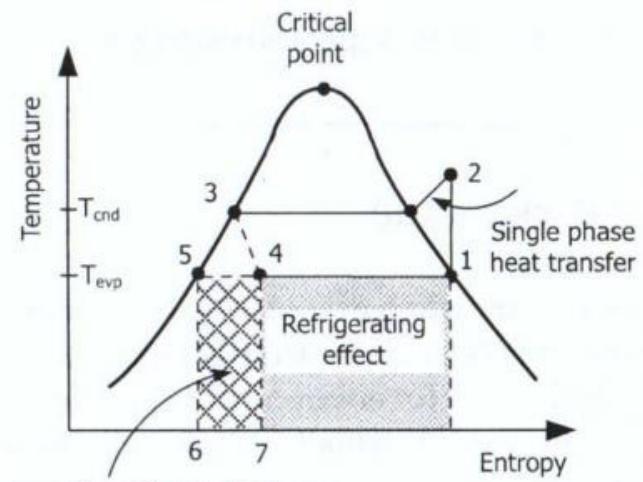

Lost cooling effect by flash gas



Figure 1: Influence of the critical point and operating temperatures on cooling capacity

The implications of the above is that for specified condensing and evaporating temperatures, different refrigerants will acquire different degree of irreversibilities, resulting in different cycle efficiencies. Using reduced temperature, $\mathrm{Tr}$, defined as $\mathrm{T} / \mathrm{T} \mathrm{crt}$, the relative positions of evaporating and condensing temperatures on the vapour dome relative to critical point temperature can be conveniently described. This provides a common basis for performance comparison among different refrigerants for a specified application. 
A refrigerant with moderate values of $\mathrm{Tr}$ in condenser and evaporator indicate a fair balance between the capacity an the efficiency, whereas $\mathrm{Tr}$ in condenser closer to unity or $\mathrm{Tr}$ in evaporator close to zero are the extreme cases which need avoiding on the above basis when selecting a refrigerant.

The slope of the saturated vapour and liquid lines are important criterion in selecting a refrigerant. Iq. 1 gives the slope of the saturated boundary on the vapour dome (T-s diagram) [9], where the subscript denotes that the respective gradients are taken along the saturation line.

$$
\left[\frac{\mathrm{dT}}{\mathrm{ds}}\right]_{\tau}=\frac{1}{\left[\frac{\mathrm{C}_{\mathrm{v}}}{\mathrm{T}}+\left[\frac{\partial \mathrm{P}}{\partial \mathrm{T}}\right]_{\mathrm{v}}\left[\frac{\mathrm{dv}}{\mathrm{dT}}\right]_{\tau}\right]}
$$

In equation 1 , the term $(\partial P / \partial T)$, is positive for almost all saturated liquids and vapours, while $[\mathrm{d} v / \mathrm{d} T]_{\mathrm{t}}$ is positive for saturated liquids and negative for saturated vapours. Among the terms in eq. 1 , the term $\left(C_{v} / T\right)$ shows the strongest influence on the slope of saturation line, vapour or liquid. On a practical note, the slope of the saturated vapour line, as given by eq.1, decides the fraction of liquid that will turn into flash gas during the expansion process; implying lower slopes corresponds to higher expansion losses (area 4-5-6-7, Fig 1).

\subsection{Potential replacement refrigerants}

Table 1 and 2 list selected properties and other related parameters of shortlisted alternatives (not necessarily on a commercial scale) for the low temperature refrigeration application below $-50{ }^{\circ} \mathrm{C}$, picked from the two lists of refrigerants and mixtures provided in the appendices A1 and $\mathrm{A} 2$.

Table 1: Selected refrigerants - Temperatures and enthalpies [10]

\begin{tabular}{|l|c|c|c|}
\hline \multicolumn{1}{|c|}{ Refrigerant } & $\begin{array}{c}\mathrm{T}_{\mathrm{NBr}} \text { or } \\
\mathrm{T}_{\text {buble }}\end{array}$ & $\mathrm{T}_{\text {crit }}$ & $\mathrm{h}_{\mathrm{fg}}$ \\
\hline R14 (FC) & -128.1 & -45.6 & 134.4 \\
\hline R170 (HC) & -88.6 & 32.2 & 489.5 \\
\hline R508A (HCFC/FC) & -87.4 & 11.0 & 156.9 \\
\hline R508B (HCFC/FC) & -87.4 & 12.1 & 166.1 \\
\hline R23 (HCFC) & -82.1 & 25.9 & 240.7 \\
\hline R116 (FC) & -78.2 & 19.9 & 116.2 \\
\hline R41 (HFC) & -78.1 & 44.1 & 488.8 \\
\hline R504 (HFC/CFC) & -57.7 & 62.1 & 195.7 \\
\hline
\end{tabular}

In the selection of refrigerants, normal boiling point is used as a screening criterion based on the requirement of positive evaporator pressure at the lowest expected temperature. Though carbon dioxide too can be considered a potential refrigerant, only halogenated refrigerants and hydrocarbons are considered in the present study. Certain FCs such as R14, R116, are not presently used much as a common low temperature refrigerants. Both these fluids have relatively higher atmospheric life and global warming potential. However, R116 is used in making both R508A and R508B.

Table 2: Selected refrigerants - Environmental and safety parameters $[7,10]$

\begin{tabular}{|l|c|c|c|}
\hline Refrigerant & $\begin{array}{c}\text { ODP } \\
(\mathrm{R} 11=1)\end{array}$ & $\begin{array}{c}\text { GWP } \\
\left(\mathrm{CO}_{2}=1\right)\end{array}$ & $\begin{array}{c}\text { Safety } \\
\text { group }^{(a)}\end{array}$ \\
\hline R14 & 0 & 5700 & $\mathrm{~A} 1$ \\
\hline R170 & 0 & $\sim 20$ & $\mathrm{~A} 3$ \\
\hline R508A & 0 & 12700 & $\mathrm{~A} 1$ \\
\hline R508B & 0 & 13000 & $\mathrm{~A} 1$ \\
\hline R23 & 0 & 12240 & $\mathrm{~A} 1$ \\
\hline R116 & 0 & 10000 & $\mathrm{~A} 1$ \\
\hline R41 & 0 & 97 & - \\
\hline R504 & 0.2 & 4000 & - \\
\hline
\end{tabular}

a - According to ASHRAE the capital letter indicates the toxicity; where A signifies non-toxic. The numeral denotes flammability; where 1 indicates no flame propagation, 2 signify rêfrigerants having moderate flammability (a lower flammability limit (LFL) of more than $0.10 \mathrm{~kg} / \mathrm{m} 3$ at $21^{\circ} \mathrm{C}$ and $101 \mathrm{kPa}$ and a heat of combustion of less than 19,000 $\mathrm{kJ} / \mathrm{kg}$ ), and 3 signify refrigerants having high flammability (an LFL of less than or equal to $0.10 \mathrm{~kg} / \mathrm{m} 3$ at $21^{\circ} \mathrm{C}$ and 101 $\mathrm{kPa}$ or a heat of combustion greater than or equal to 19,000 $\mathrm{kJ} / \mathrm{kg}$ ).

\subsection{Refrigerant and mixture properties}

In this study the required thermal-physical properties of different refrigerants, the graphs of variation of properties on T-s plane and theoretical performance parameters of vapour compression cycles with selected refrigerants were obtained using a purpose written structured computer simulation. This simulation programme was written in Fortran 90, and consist of over 40 subroutines and data modules and validated using existing data for mixtures. Further, the simulation incorporate accurate and most recent mixing rules and equations of state for refrigerant mixtures [10]. 


\section{Properties and performances}

\subsection{Saturation temperature, pressure and vapour volumes}

Fig. 2 presents the variation of reduced temperatures ( $\mathrm{T} / \mathrm{T}_{\mathrm{crt}}$ ) of the selected refrigerants (given in table1) withinevaporation temperatures in the range -50 to $-100{ }^{\circ} \mathrm{C}$. It appears that the variation of reduced temperature of R116 closely follows that of R503. Also, the mixtures R508A and $R 508 B$ have close reduced temperatures to those of R503. On the other hand, R23 and R170 show a behaviour very close to R13. Both R41 and R504 have lower reduced temperatures compared to R13 and R503. Among the refrigerant considered, R14 exhibit relatively higher reduced temperatures.

Fig. 3 presents the variation saturated vapour volumes, presented relative to those at $-50{ }^{\circ} \mathrm{C}$ for each refrigerant. This demonstrates the order and the rate of change of vapour volume when operating at evaporation temperatures below -50 ${ }^{\circ} \mathrm{C}$. Down to about $-65^{\circ} \mathrm{C}$, the changes in vapour volumes are within about two folds of those at $-50^{\circ} \mathrm{C}$. However, below $-65^{\circ} \mathrm{C}$, vapour volume increases at a higher rate, with R504 showing the highest gradient, while R41 and R116 showing the lowest rate of change. The changes in vapour volume of R508A, R508B, R23 closely follow $\mathrm{R} 13$ and R503. Below about $-90^{\circ} \mathrm{C}, \mathrm{R} 14$ show a lower rate of change of volume compared to R503 and R13.

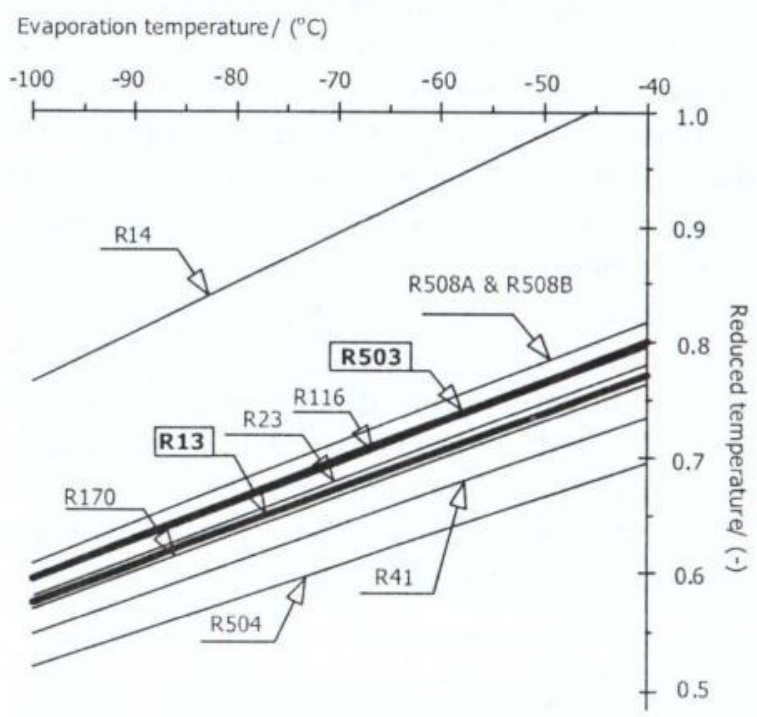

Figure 2: Reduced temperatures

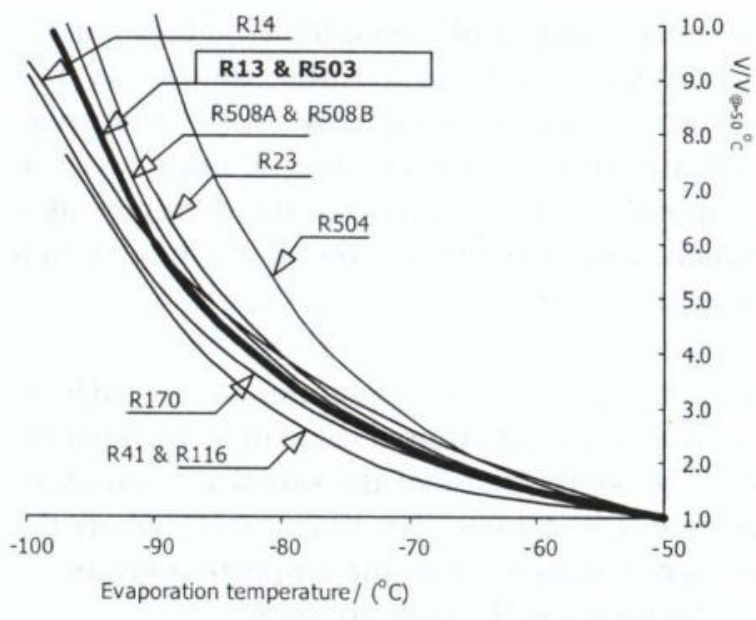

Figure 3: Saturated vapour volumes

Fig. 4 presents the variation of saturated vapour pressure with evaporation temperature, relative to the atmospheric pressure. The refrigerants show different degree of rate of change of pressure. R41, R116, R23 show evaporating pressures above atmospheric above $-75^{\circ} \mathrm{C}$, where for R170, R508A, R508B evaporation will be above atmospheric pressure at temperatures above $-91^{\circ} \mathrm{C}$. R504 will have lower evaporation pressure than the atmospheric pressure below about $-55^{\circ} \mathrm{C}$. R14 shows relatively higher vapour pressure making it a good candidate for lower evaporating temperatures, even below $-100{ }^{\circ} \mathrm{C}$, a fact supported by its relatively higher reduced temperatures of evaporation and condensation of R14 (in Fig 2).

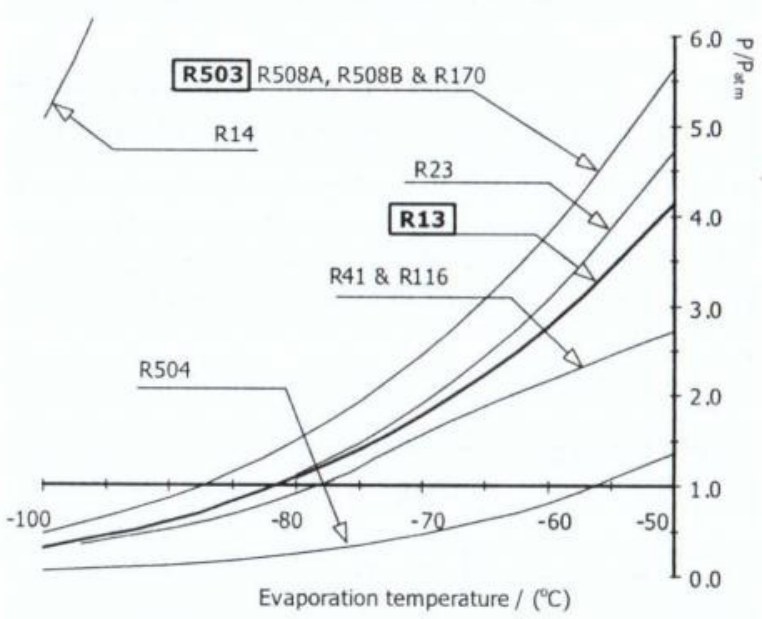

Figure 4: Saturated vapour pressures

As indicated in Fig. 4, the operating pressure of $\mathrm{R} 14$ at $-100^{\circ} \mathrm{C}$ is well above atmospheric pressure $(\approx 514 \mathrm{kPa})$, indicating positive evaporator pressure down to about $-128^{\circ} \mathrm{C}$ (Table 2). 
4.2 Factors affecting efficiency and performance

\section{a) Compressor discharge temperature and flash gas losses}

Fig. 5 presents the shape of vapour domes of the selected refrigerants on temperature - entropy (T-s) plane. For each refrigerant, temperatures -100 and $-50^{\circ} \mathrm{C}$ are marked (in dotted lines) to provide an idea of the locations of corresponding saturation pressures relative to respective critical point. Among the refrigerants considered, R41 and R23 have fairly symmetrical vapour domes, where as R170 and R13 show somewhat sharp converging behaviour towards critical point. R116 and R14 have skewed vapour domes to the right to certain degree. However, the selected operating temperature ranges are situated very close to critical point in the case of R14, and much further away from critical point in the case of R116 and R41. Fig 5 also shows that R116 exhibit the risk of compression back into wet region under certain operating circumstances, which is not desirable feature for reciprocating compressors. Another observation is that R170 could be used at much lower temperatures compared to $-100^{\circ} \mathrm{C}$.
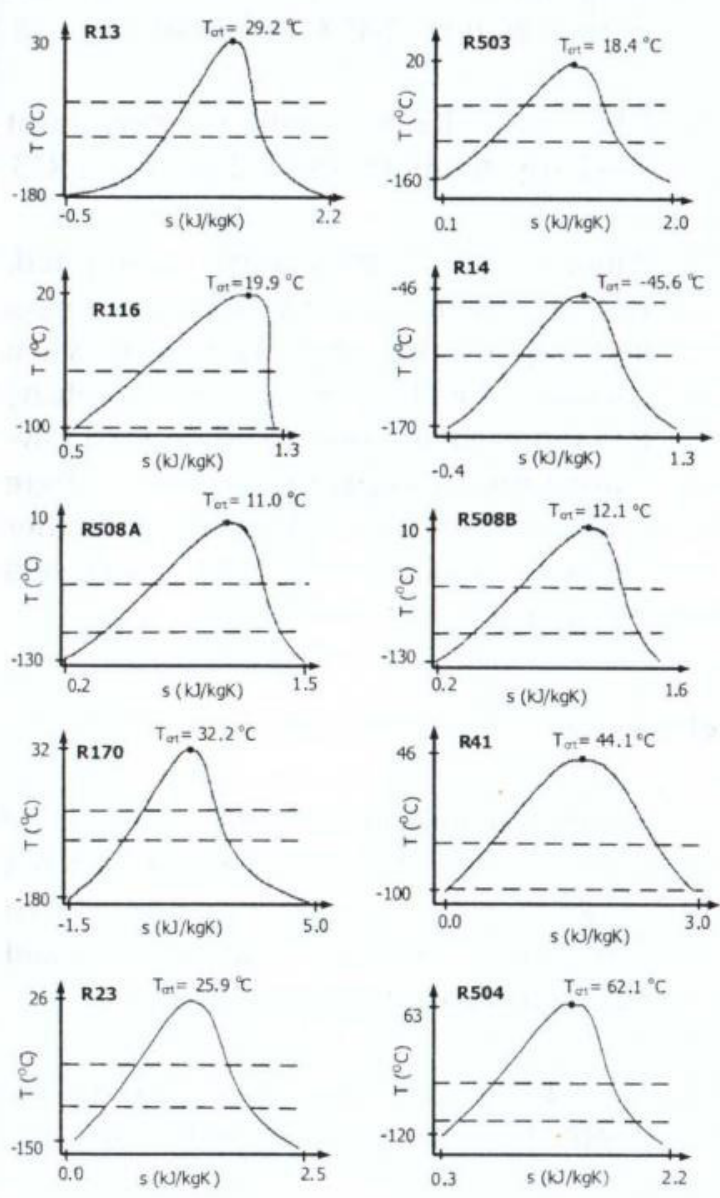

Figure 5: Shape of vapour domes on T-s plane
Fig. 6 presents the vapour quality at the evaporator entry when using each refrigerant in a vapour compression cycle with condensing and evaporating at -50 and $-90^{\circ} \mathrm{C}$ respectively. In the Fig., R14 shows the highest vapour quality; this is due to operation close to the critical point and relatively lower slope of saturated liquid line. R170, R504, R41, R508B and R23 all show lower vapour quality than R13 and R503. Among the refrigerants, R41 shows the lowest expansion losses, corresponding to the lowest fraction of cooling capacity losses during expansion.

Fig. 7 presents the vapour discharge temperatures from the compressor when isentropic compression is carried out from few selected evaporation temperatures to condensing temperature of $-50{ }^{\circ} \mathrm{C}$. R41 shows the highest discharge temperature whereas R116 shows the lowest. Though these two refrigerants, R41 and R116, exhibit similarities in certain behavioral aspects, such as vapour volumes and pressures, here they form the extreme cases among the considered refrigerants. Discharge temperatures of R508A and R14 follow closely those of R13 whereas R508B and R170 show somewhat similar temperatures as R503

In practice, there are fluctuations in the operating conditions of low temperature vapour compression systems; for example, the cascade condenser is exposed to fluctuations of temperatures and pressures during operation [5]. In such cases, if the discharge superheat is more than about 40 to $50{ }^{\circ} \mathrm{C}$, to avoid the risk of thermal fatigue of the heat exchanger, desuperheating of entering refrigerant vapour will be required. The data show that R503, R170, R504, R41, R116, R508B and R23 show discharge superheat above 40 degrees at Tevp of $-100^{\circ} \mathrm{C}$.

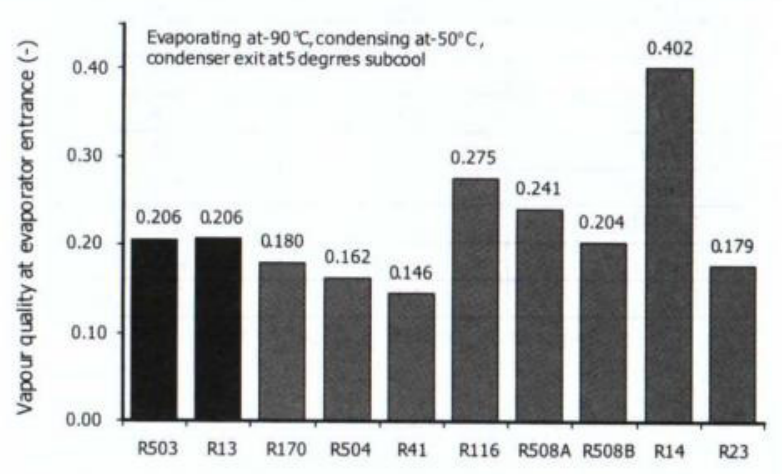

Figure 6: Flash gas formation 
Cooling capacities of the refrigerants are presented in table 3 on both unit mass and volume bases. The first category corresponds to likely mass flow rate required to obtain a specified capacity, so that heat transfer and pressure drop estimates can be performed for the selected refrigerant and heat exchangers and pipe lines can be sized appropriately. The latter category directly relates to the size (volume flow rate) of the compressor. On mass basis R170 and R41 show the best performances where as on volume basis R14 has the best performances. One can see that, on the mass basis R23, R41, R504 and R170 have better performances than both replacing refrigerants $R 13$ and $R 503$. On volume basis, only R508A, R508B and R14 have superior performance to the two replaced refrigerants.

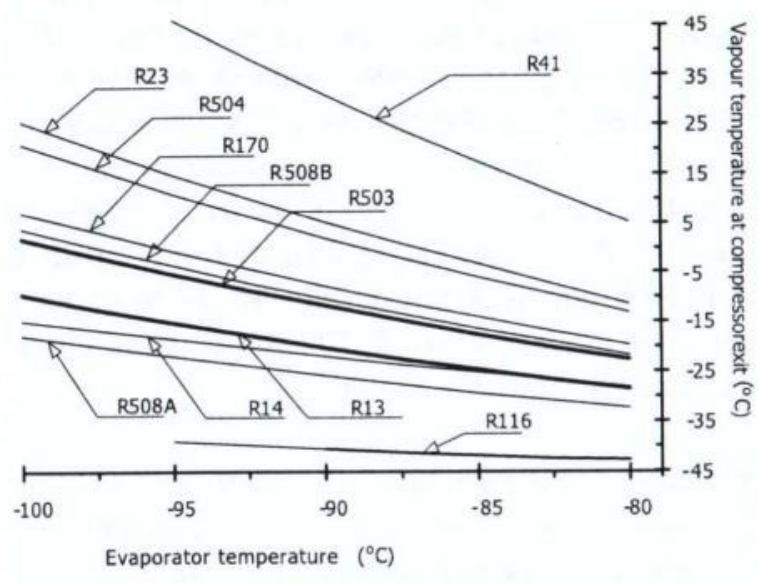

Figure 7: Discharge temperatures

b) Cooling capacity

Table 3: Cooling and volumetric capacities

\begin{tabular}{|l|c|c|}
\hline Refrigerant & $\begin{array}{c}\text { Cooling } \\
\text { capacity } \\
\left(\mathrm{kW} / \mathrm{kg} \mathrm{s}^{-1}\right)\end{array}$ & $\begin{array}{c}\text { Volumetric } \\
\text { capacity } \\
\left(\mathrm{kW} / \mathrm{m}^{3}\right)\end{array}$ \\
\hline R503 & 144.1 & 3.8 \\
\hline R13 & 122.0 & 3.2 \\
\hline R170 & 404.0 & 1.4 \\
\hline R504 & 216.9 & 0.4 \\
\hline R41 & 433.6 & 0.8 \\
\hline R116 & 88.3 & 3.4 \\
\hline R508A & 121.1 & 4.3 \\
\hline R508B & 129.5 & 4.0 \\
\hline R14 & 66.6 & 42.8 \\
\hline R23 203.5 & 2.1 \\
\hline \multicolumn{2}{|c|}{ Tevp $^{2}-90, T_{\text {cnd }}=-50$, dT $_{\text {sht }}=5, \mathrm{dT}_{\text {sc }}=5^{\circ} \mathrm{C}$} \\
\hline
\end{tabular}

\section{Conclusions}

Performances of R170, R41, R116, R504, R508A, $\mathrm{R} 508 \mathrm{~B}$ and R14 were evaluated for their suitability in low temperature applications with evaporation below $-50{ }^{\circ} \mathrm{C}$. The analysis was based on the thermal-physical properties of the refrigerants and the performance of theoretical vapour compression cycle. The following can be concluded based on the findings.

- R116 exhibit a similar reduced temperature behaviour to R503, and R270 to R13

- Mixtures R508A and R508B closely follow saturated vapour volumes of both R13 and R503, making the two mixtures potential drop-in alternative refrigerants in system retrofit.

- None of the considered refrigerants show closely matching saturated vapour pressure behaviour to R13 or R513

- R170 shows better cooling performances per circulated unit mass at lower temperatures and can be used for evaporation at $-100^{\circ} \mathrm{C}$ or below.

- R14 and R508A follow refrigerant discharge temperatures behaviour of R13

- Among the refrigerants considered, R14 shows the highest flash gas losses and vapour pressures. However, when considered with its reduced temperature, R14 represent a good candidate for a lowtemperature refrigerant mixtures where undesirable features of R14 (e.g. higher vapour pressure) could be made less prominent.

\section{References}

1. Leelananda Rajapaksha, 2007, Influence of special attributes of zeotropic refrigerant mixtures on design and operation of vapour compression refrigeration, Energy conservation and management, vol 48 (2), pp 539-545

2. Horst Kruse, 2000, Refrigerant use in Europe, ASHRAE Journal, vol 42 (9), pp 16 - 24. 
3. David A Didion, 1999, The application of HFC refrigerants, Proc. of International congress of Refrigeration, September 1999, Australia

4. Piotr A Domanski, 1999, Evolution of refrigerant applications, Proc. of Int. congress on refrigeration, May 1999, Italy.

5. ASHRAE Handbook, Refrigeration, Chapter 39, 1998

6. Stegmann Rudy, 2000, Low Temperature refrigeration, ASHRAE Journal, vol 42(1), pp 42-50.

7. James M Calm, 2003, The four R's for responsible response to refrigeration regulation, Engineered systems, October 2003.

8. James M Calm and David A Didion, 1999, Trade-offs in refrigerant selection: past, present and future, Int. J Refrig., vol 21, no4, pp 308-321.

9. Morrison G, 1994, The shape of the temperatureentropy saturation boundary, Int. J. Rrefrig., vol 17, No 7, pp 494-504.

10. McLinden $M$, Klein A S, Lemmon $E$ W and Peskin P A, 1998, REFPROP, version 6.01, NIST, USA. 


\section{Appendix 1}

Table A1: Single component refrigerants [10]

\begin{tabular}{|c|c|c|c|}
\hline \multirow[b]{2}{*}{ Refrigerant } & \multirow[b]{2}{*}{$\begin{array}{l}\text { Haloge } \\
\text { n group }\end{array}$} & \multicolumn{2}{|c|}{ At $101.325 \mathrm{kPa}$} \\
\hline & & $\begin{array}{l}\mathrm{T}_{\text {bpt }} \\
\left({ }^{\circ} \mathrm{C}\right)\end{array}$ & $\begin{array}{c}\mathrm{h}_{\mathrm{fg}} \\
(\mathrm{kJ} / \mathrm{kg})\end{array}$ \\
\hline R14 & $\mathrm{FC}$ & -128.1 & 134.4 \\
\hline $\mathrm{R} 170$ & $\mathrm{HC}$ & -88.6 & 489.5 \\
\hline R23 & HCFC & -82.1 & 240.7 \\
\hline R13 & CFC & -81.3 & 149.3 \\
\hline R116 & $\mathrm{FC}$ & -78.2 & 116.2 \\
\hline R41 & $\mathrm{HFC}$ & -78.1 & 488.8 \\
\hline R32 & HFC & -51.7 & 381.8 \\
\hline R125 & $\mathrm{HFC}$ & -48.1 & 163.9 \\
\hline R1270 & $\mathrm{HC}$ & -47.7 & 439.2 \\
\hline R143a & $\mathrm{HFC}$ & -47.2 & 227.1 \\
\hline R290 & $\mathrm{HC}$ & -42.1 & 425.4 \\
\hline $\mathrm{R} 22$ & $\mathrm{HCFC}$ & -40.8 & 233.7 \\
\hline R115 & CFC & -38.9 & 125.4 \\
\hline R218 & $\mathrm{FC}$ & -36.8 & 105.2 \\
\hline R12 & $\mathrm{CFC}$ & -29.8 & 166.2 \\
\hline $\mathrm{R} 134 \mathrm{a}$ & $\mathrm{HFC}$ & -26.1 & 217.0 \\
\hline R152a & HFC & -24.0 & 329.9 \\
\hline R227ea & $\mathrm{HFC}$ & -15.6 & 131.9 \\
\hline R124 & HCFC & -12.0 & 165.8 \\
\hline $\mathrm{R} 142 \mathrm{~b}$ & HCFC & -9.0 & 222.7 \\
\hline RC318 & FC & -6.0 & 116.8 \\
\hline R236fa & $\mathrm{HFC}$ & -1.4 & 160.3 \\
\hline R600 & $\mathrm{HC}$ & 0.5 & 385.7 \\
\hline R114 & CFC & 3.6 & 136.0 \\
\hline R236ea & $\mathrm{HFC}$ & 6.2 & 165.2 \\
\hline $\mathrm{R} 600 \mathrm{a}$ & $\mathrm{HC}$ & 11.6 & 366.7 \\
\hline R245fa & HFC & 14.9 & 196.7 \\
\hline R11 & CFC & 23.7 & 181.4 \\
\hline R245ca & HFC & 25.1 & 197.4 \\
\hline R123 & HCFC & 27.8 & 170.2 \\
\hline R141b & HCFC & 32.1 & 223.1 \\
\hline R113 & CFC & 47.6 & 144.3 \\
\hline
\end{tabular}

\section{Appendix 2}

Table A2: Refrigerant mixtures [10]

\begin{tabular}{|c|c|c|c|c|}
\hline \multirow[b]{2}{*}{$\begin{array}{l}\text { Refrigerant } \\
\text { Mixture }\end{array}$} & \multirow[b]{2}{*}{ it Components } & \multicolumn{3}{|c|}{ At $101.325 \mathrm{kPa}$} \\
\hline & & \multirow{2}{*}{$\begin{array}{l}\begin{array}{l}\mathrm{T}_{\text {bub }} \\
\left({ }^{\circ} \mathrm{C}\right)\end{array} \\
-87.5 \\
\end{array}$} & \multirow{2}{*}{$\begin{array}{l}\mathrm{T}_{\text {de }} \\
{ }^{w} \\
\left({ }^{\circ} \mathrm{C}\right) \\
-87.5\end{array}$} & \multirow{2}{*}{ 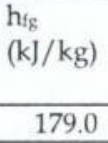 } \\
\hline R503 & R23/R13 & & & \\
\hline R508A & R23/R116 & -87.4 & -87.4 & 156.9 \\
\hline R508B & R23/R116 & -87.4 & -87.0 & 166.4 \\
\hline R504 & R32/R115 & -57.7 & -56.2 & 195.7 \\
\hline $\mathrm{R} 410 \mathrm{~A}$ & $\mathrm{R} 32 / \mathrm{R} 125$ & -51.6 & -51.6 & 271.5 \\
\hline R410B & $\mathrm{R} 32 / \mathrm{R} 125$ & -51.5 & -51.4 & 260.7 \\
\hline R402A & R125/R290/R22 & -49.2 & -47.1 & 194.3 \\
\hline R402B I & R125/R290/R22 & -47.2 & -44.9 & 210.1 \\
\hline R507A & R125/R143a & -47.1 & -47.1 & 196.1 \\
\hline R407B & R32/R125/R134a & -46.8 & -42.4 & 200.0 \\
\hline R404A & R125/R143a/R134a & -46.6 & -45.8 & 200.1 \\
\hline R408A & R125/R143a/R22 & -45.5 & -45.0 & 24.9 \\
\hline R502 & R22/R115 & -45.3 & -45.0 & 173.3 \\
\hline R407A & R32/R125/R134a & -45.2 & -38.7 & 234.3 \\
\hline R407C & $\mathrm{R} 32 / \mathrm{R} 125 / \mathrm{R} 134 \mathrm{a}$ & -43.8 & -36.7 & 248.0 \\
\hline R407E & R32/R125/R134a & -42.8 & -35.6 & 257.0 \\
\hline R411B & R1270/R22/R152a & -41.6 & -40.3 & 243.4 \\
\hline R509A & R22/R218 & -40.7 & -40.6 & 159.8 \\
\hline R501 & R22/R12 & -40.5 & -40.4 & 218.9 \\
\hline R411A & R1270/R22/R152a & -39.7 & -37.2 & 249.6 \\
\hline R407D 1 & R32/R125/R134a & -39.4 & -32.7 & 240.3 \\
\hline R409B I & R22/R124/R142b & -36.5 & -29.7 & 219.6 \\
\hline R401B I & R22/R152a/R124 & -35.7 & -30.8 & 228.3 \\
\hline R409A I & $\mathrm{R} 22 / \mathrm{R} 124 / \mathrm{R} 142 \mathrm{~b}$ & -35.4 & -27.5 & 220.2 \\
\hline R401A I & R22/R152a/R124 & -34.4 & -28.8 & 226.7 \\
\hline R500 & R12/R152a & -33.6 & -33.6 & 202.5 \\
\hline R406A I & $\mathrm{R} 22 / \mathrm{R} 600 \mathrm{a} / \mathrm{R} 142 \mathrm{~b}$ & -32.7 & -23.6 & 241.5 \\
\hline R401C & $\mathrm{R} 22 / 152 \mathrm{a} / 124$ & -30.5 & -23.8 & 217.3 \\
\hline
\end{tabular}

Note: Bubble point temperatures (Tbub) are given instead of boiling point temperature. 